\title{
Limitations of the cancer stem cell theory
}

\author{
Luca Vezzoni · Giorgio Parmiani
}

Received: 15 September 2008/ Accepted: 15 September 2008/Published online: 1 October 2008

(C) Springer Science+Business Media B.V. 2008

\begin{abstract}
Cancer stem cells (CSCs) can be operationally defined as a subset of neoplastic cells which are responsible for the growth and re-growth of primary and metastatic tumors. Although the existence of perpetually dividing cells is a logical necessity to explain the malignant properties of human tumors, experimental data supporting their existence have only recently been obtained. New knowledge in basic stem cell biology and the availability of several cell surface markers for the definition and isolation of small subsets of immature cells coupled to the use of the classical model of xenotransplantation in immune deficient mice has identified putative CSCs in several solid tumors such as mammary, colon, brain, pancreas, prostate, melanoma and others. However, the theory must be considered as still in its infancy, since tumors grown in mice only partially recapitulate the biology of human cells. In addition, whether the "transformed" cell is the neoplastic counterpart of a normal stem cell or whether complete malignant behaviour can occur in a more differentiated cell has still to be demonstrated. In spite of these difficulties, the CSC hypothesis could be of clinical relevance, especially in the definition of new ways to assay drug sensitivity of primary human tumors.
\end{abstract}

L. Vezzoni $(\bowtie) \cdot$ G. Parmiani

Department of Oncology, San Raffaele Scientific Institute, Milan, Italy

e-mail: luke.vez@alice.it
Keywords Cancer stem cell - Tumor xenotransplantation - Differentiation . Tumor heterogeneity

\section{Background}

Defining "stem cells" is not so easy. Most researchers agree that the only true totipotent stem cell is the zygote and, possibly, the earliest blastomere (Jaenisch and Young 2008). Pluripotent stem cells are those of the blastocyst inner cells mass which in mouse give rise to the so called "embryonal stem cells" (ESC), which can give rise to all cells but not the trophoectodermal ones. Multipotent cells are usually defined as those able to produce cells pertaining to multiple cell types of the same lineage: haematological stem cells (HSC) are the best defined example of this category. Unipotent stem cells form only one cell type, as the spermatogonial stem cells do.

A stem cell is one which is able to self-renew while generating other cells which commit to differentiation. Recent studies have elucidated a further characteristic of stem cells which seems of great physiological and pathological relevance: the ability to divide asymmetrically, giving rise to an identical cell remaining in situ and to a daughter cell which starts the differentiation process, being "committed" to a particular lineage (Knoblich 2008). This feature is more a logical necessity than an experimental 
demonstration, since it is needed to explain the continuous renewal of tissues such as the skin or the intestine epithelium. However, the alternative possibility that a finite, albeit large, number of stem cells exist after birth and provide differentiated cells for all the life of the organism by stochastic activation and commitment of both daughter cells to differentiation, has not yet been ruled out. Indeed, at least for the female germline cells, whose stem cell pool becomes depleted in the fourth-fifth decade of human female life, this alternative could hold true.

Recently, the concept of stem cells has also entered the cancer field (Lobo et al. 2007). Several seminal papers have suggested the existence of a small percentage of cells which are responsible for the initial growth, maintenance and, more importantly, re-growth of all the tumor cells after therapy (Al-Hajj et al. 2003; Bao et al. 2006; Chiba et al. 2006; Dalerba et al. 2007; Dontu et al. 2007; Fang et al. 2005; Galli et al. 2004; Ho et al. 2007; Lapidot et al. 1994; Li et al. 2007; Patrawala et al. 2006; Piccirillo et al. 2006; Ponti et al. 2005; Prince 2007; Ricci-Vitiani et al. 2007; Schatton et al. 2008; Singh et al. 2003, 2004; Szotek et al. 2006; Wang et al. 2007). In addition to being biologically relevant, this concept might be of great clinical importance, since it could explain the clinical observation that in spite of the fact that more than $99 \%$ of tumor cells can often be destroyed by chemotherapy, many tumors are eventually able to grow again.

\section{The experimental plan}

The studies performed follow a general scheme (Fig. 1). Cells from primary tumors or cell lines are separated by FACS or other classical means in several fractions defined by surface markers or other properties, some of which are known to be shared by normal stem cells. Table 1 shows several markers used in different tumors: some are common to many histological types while others are, so far, more restricted. These fractions are then individually inoculated in immunocompromised mice and their ability to form tumors is scored. In many reports it has been shown that the ability to form tumors differs from fraction to fraction and that the populations bearing markers associated to "stemness" give rise to tumors with a frequency that is statistically different from that produced by other fractions. Some of these data are summarised in Table 2. Additional common features of the experiments are the ability of the transplanted CSCs to recapitulate the original heterogeneity of the tumors and the maintenance of their properties even after serial transplantation since CSCs from both the original and transplanted tumors

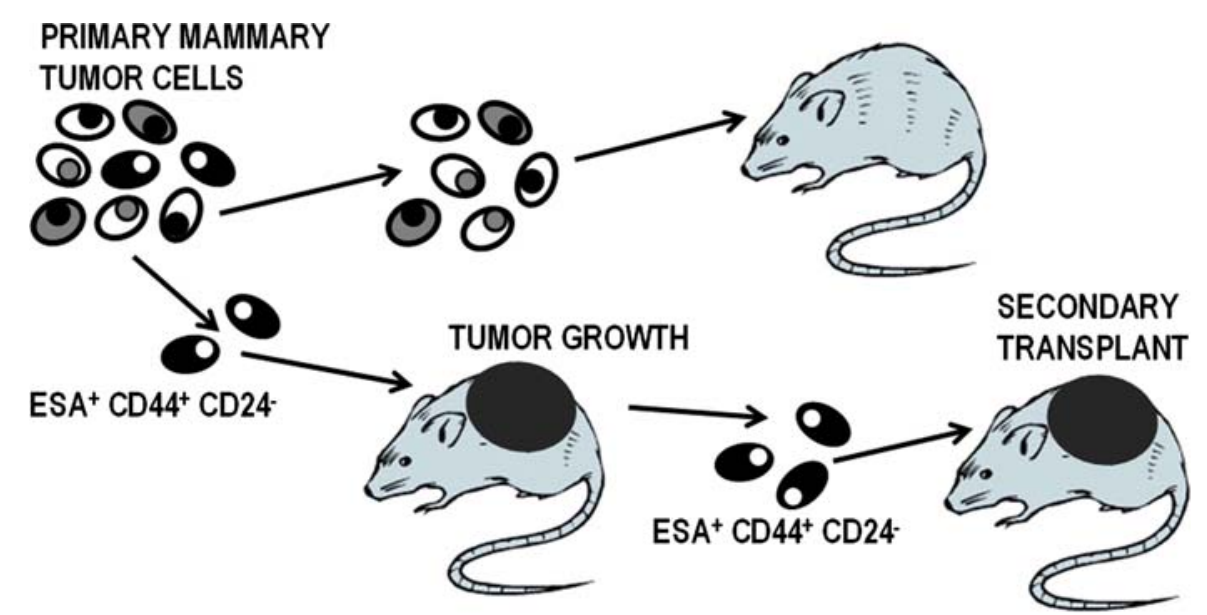

Fig. 1 Schematic representation of the xenotrasplantation approach to the study of cancer stem cells. The mammary cancer is taken as example. Tumor cells are dissociated from a primary breast cancer and sorted according to the expression of surface cell markers. The various fractions are separately injected into the immunocompromised mouse and tumor formation is followed. In secondary transplants, the cells from the transplanted tumor are again dissociated, sorted and reinjected into another immune compromised animal 
Table 1 Cancer stem cell markers of histologically different human tumors ${ }^{\mathrm{a}}$

\begin{tabular}{|c|c|c|c|}
\hline Tumor & Markers & Frequency $(\%)$ & References \\
\hline Leukemia (AML) & $\mathrm{CD} 34^{+}, \mathrm{CD} 38^{-}, \mathrm{Lin}^{-}$ & $0.0004^{\mathrm{b}}$ & Bonnet and Dick (1997) \\
\hline \multirow[t]{2}{*}{ Breast cancer } & $\mathrm{ESA}^{+}, \mathrm{CD} 44^{+}, \mathrm{CD} 24^{-/ \text {low }}$ & $11-35$ & Al-Hajj et al. (2003) \\
\hline & $\mathrm{CD} 44^{+}, \mathrm{CD} 24^{-}, \mathrm{Oct}-4^{+}$ & $10-20$ & Ponti et al. (2005) \\
\hline Brain tumors & $\mathrm{CD} 133^{+}$ & $5-30$ & Galli et al. (2004) \\
\hline \multirow[t]{3}{*}{ Colorectal cancer } & $\mathrm{CD} 133^{+}$ & $1.8-24.5$ & Ricci-Vitiani et al. (2007) \\
\hline & $\mathrm{CD} 44^{+}, \mathrm{CD}_{166^{+}}, \mathrm{ESA}^{+}$ & $1.8-9.2$ & Dalerba et al. (2007) \\
\hline & $\mathrm{CD}_{133}{ }^{+}$ & 0.057 & O'Brien et al. (2007) \\
\hline Melanoma & $\mathrm{ABCB}^{+}$ & $1.6-20.4$ & Schatton et al. (2008) \\
\hline Pancreatic cancer & $\mathrm{ESA}^{+}, \mathrm{CD}_{4} 4^{+}, \mathrm{CD} 24^{+}$ & $0.2-0.8$ & Li et al. (2007) \\
\hline Prostate cancer & $\mathrm{CD}_{4} 4^{+}, \mathrm{CD} 133^{+}$(Hoechst excluding cells) & $0.04-0.2$ & Patrawala et al. (2007) \\
\hline Ovarian cancer & Side population (Hoechst excluding cells $\mathrm{CD} 44^{+}$) & N.D. & Szotek et al. (2006) \\
\hline Head and neck cancer & $\mathrm{CD} 44^{+}, \mathrm{CK} 5 / 14^{+}, \mathrm{BMI}^{-}{ }^{+}$ & $<10$ & Prince (2007) \\
\hline
\end{tabular}

${ }^{a}$ None of these markers are expressed exclusively by stem cells

b Frequency of the leukemia-initiating cell in peripheral blood of AML patients is 1 engraftment unit/250.000 cells

N.D., Not determined

Table 2 Tumor cell initiating potential according to selected markers

\begin{tabular}{llcc}
\hline Hystological type & Cell source & Cell dose & $\begin{array}{l}\text { Total number of } \\
\text { mice with tumors (\%) }\end{array}$ \\
\hline $\begin{array}{l}\text { Colorectal cancer } \\
\text { (Ricci-Vitiani et al. 2007) }\end{array}$ & Bulk & $1 \times 10^{6}$ & $19 / 64(29.69)$ \\
& & $3 \times 10^{3}$ & $15 / 26(57.69)$ \\
& CD133 $^{-}$ & $1 \times 10^{4}$ & $19 / 32(59.38)$ \\
& & $5 \times 10^{3}$ & $0 / 10(0)$ \\
Colorectal cancer & Bulk & $1 \times 10^{4}$ & $0 / 20(0)$ \\
(O'Brien et al. 2007) & & $1 \times 10^{4}$ & $0 / 8(0)$ \\
& & $5 \times 10^{4}$ & $4 / 10(40)$ \\
& CD133 $^{+}$ & $1 \times 10^{5}$ & $10 / 10(100)$ \\
& & $1 \times 10^{2}$ & $1 / 4(25)$ \\
& & $5 \times 10^{2}$ & $5 / 6(83.33)$ \\
Colorectal cancer & & $1 \times 10^{3}$ & $7 / 7(100)$ \\
(Dalerba et al. 2007) & & $1 \times 10^{5}$ & $0 / 8(0)$ \\
& & $2.5 \times 10^{5}$ & $1 / 9(11.1)$ \\
& & $2 \times 10^{2}$ & $21 / 28(75)$ \\
& & $4 \times 10^{2}$ & $16 / 20(80)$ \\
& & $2 \times 10^{3}$ & $17 / 19(89,47)$ \\
& & $5 \times 10^{3}$ & $4 / 5(80)$ \\
& & $4 \times 10^{2}$ & $0 / 10(0)$ \\
& & $2 \times 10^{3}$ & $1 / 30(3,33)$ \\
& & $0 / 5(0)$ \\
\hline
\end{tabular}

can give rise to tumors similar to those from which they originated.

The significance of all these findings are not completely clear. Strictly speaking, they only demonstrate that the xenotransplantability in an immunocompromised host of human neoplasias is the property of a small number of cells, which can reproduce the heterogeneity of the tumor, while the 
remaining $>95 \%$ of the cells are not capable of malignant growth in a heterologous host. This property is taken as evidence that also in vivo and in homine these cells are the only ones whose replication is responsible for the growth of the tumor and, more importantly, that they are the ones which are not killed by chemotherapy, thus being responsible for the recurrence of the neoplasia in humans. This seems reasonable but has not been formally proven and there is the possibility that the xenotransplantation model underestimates the frequency of cells able to reproduce tumors (Kelly et al. 2007; Adams et al. 2007).

Reasons for which this conclusion could be too extreme include (Wicha et al. 2006) the following arguments:

(a) Disruption of the primary tumor structure: recent studies have emphasized the fact that in primary tumors different populations interact with each other and with normal ones. The disruption of these interactions could alter the behaviour of neoplastic cells which could lose some of their malignant features.

(b) Cell damage during the isolation of cell populations: the procedure for fraction isolation is stressful to the cell and activate intracellular mechanisms (for example: p53 activation) impairing the growth potential of the cell; in addition, the procedure often involves the use of proteolytic enzymes which could remove important molecules from the cell membrane.

(c) The transplantation into tissue environments which are often different from the normal one could make the growth of the cells difficult.

\section{CSC theory sensu stricto and sensu lato}

A major limitation of the CSC hypothesis is however the definition of CSC. The term "cancer stem cell" has acquired broad usage in the last few years, following the appearance in the scientific and social arena of the embryonal and adult stem cells, which are of great importance for their possible role in regenerative medicine. This has lead to some confusion, since the CSC term seems now to be used with two different meanings, which have different consequences for the hypothesis itself.
According to one interpretation, which we could dub the CSC theory "sensu stricto" (in the strictest sense), the existence of CSCs would mean that the cells responsible for tumor growth are the neoplastic counterpart of a normal stem cell of the tissue from where the tumor originated (Fig. 2, panel A). This interpretation seems suggested by the technical approach used to identify CSCs, since most studies use markers known to be present in normal stem cells in order to isolate CSCs. This would imply that the original event(s) leading to neoplastic transformation occurred in a normal tissue-specific adult stem cells, whose deregulation is responsible for the excessive auto-reproduction and the production of daughter cells maintaining, to some extent, the ability to differentiate, explaining the heterogeneity of the tumor. The best example that this could really occur is the human chronic myeloid leukaemia (CML), in which all the hematological lineages are involved and bear the same Philadelphia chromosome marker, which is the hallmark of the disease. The original mutation(s) allow for maintenance of a complete differentiation capacity, although subsequent events could change this condition, limiting this ability to differentiate, as occurs in the so-called "blastic crisis". Many other human leukemias could be explained by a mutation in a "bona fide" stem cell with loss of the ability to complete all the differentiation steps. The theory of leukemias as expansion of clones frozen at some specific stage of the maturation (Greaves and Janossy 1978) is compatible with the CSC theory "sensu stricto", assuming that the mutation occurred at the level of an HSC cell in genes which are involved in "committing" cells to different lineages, leading to an imbalance in normal differentiation of the various lineages.

The "sensu stricto" CSC theory is obviously untrue in several human lymphoid neoplasias. Both $\mathrm{T}$ and $\mathrm{B}$ lymphoid cells rearrange their genes during their maturation, well after the formation of the committed lymphoid progenitor. In the T-cell lineage, TCR rearrangement occurs in the thymus and is known to some extent. Every rearrangement is unique, and had the mutation occurred in the HSC, cells from pre-T and $\mathrm{T}$ lymphoid leukemias would bear polyclonal rearrangements, since every daughter cell would rearrange its TCR in a unique way. This is not the case, since these leukemias have clonal TCR rearrangements. The same is true for B-cell neoplasias. 

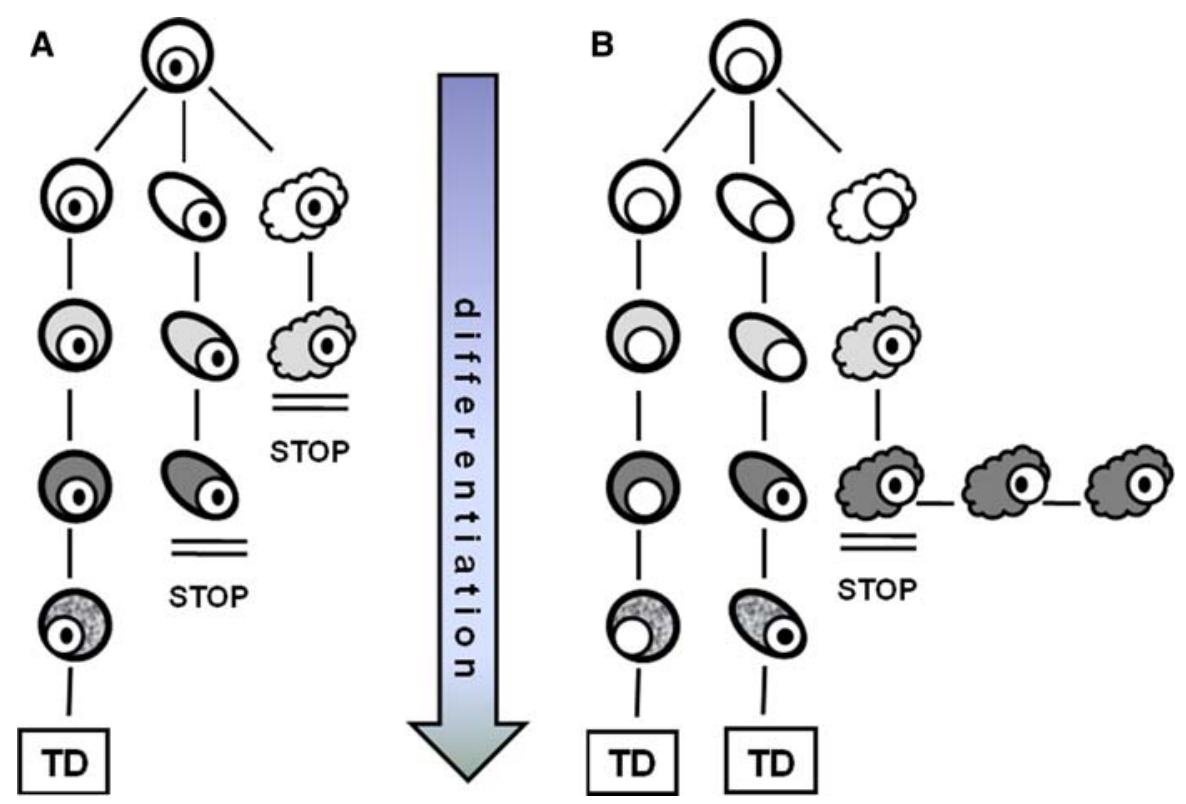

Fig. 2 Schematic representation of the cell targeted by transforming mutation(s) and of the possible consequences on differentiation and neoplastic cell growth. (Panel A) The mutation occurred in a true "stem cell". This mutation does not alter the differentiation potential of the lineage(s) and the tumor is composed of cells at various differentiation stages including the terminal one. Alternatively, the mutation in the stem cell does not allow for complete differentiation and a block at various levels occurs. All the mentioned cases are compatible with the CSC theory "sensu stricto". (Panel B) The mutation does not occur in a true immature stem cell.

The most evident case are B-cell CLL and myeloma, in which monoclonal immunoglobulin are produced.

Irreversible modifications of the genome occurring at specific advanced stages of maturation are so far known only for lymphoid cells, therefore it is not possible to investigate neoplasias arising from other tissue with this approach. However, some human neoplasias, such as thyroid or prostate cancers, are of such a low-grade malignancy, which are hardly compatible with a theory of CSC sensu stricto. In addition, experiments in transgenic mice also suggest that mutations arising in more differentiated cells can give rise to tumors. In these models, oncogene activity can be directed to specific differentiation stages by putting them under the control of specific promoter/enhancers which are active only on differentiated cells (Hanahan 1989): tumors arising in this way clearly show that the occurrence of the transforming event in a normal stem cell is not an absolute

Therefore normal differentiation can take place (at least before the neoplastic cells invades all the niches of the normal stem cells), as shown in the left lane. The mutation occurs in a more differentiated cell which maintains the ability to differentiate (central lane). Finally, the mutation in a differentiated cell does not allow for terminal differentiation, giving rise to an exaggerated growth of cells frozen at a specific differentiative stage. These are examples of the CSC "sensu lato" theory. These examples do not cover all the possibilities of cancer development

requirement, but that also more differentiated cells can sustain the growth of fully malignant tumors.

"Sensu lato" (in the broad sense) CSC theory could be defined as suggesting that the malignant growth properties of a tumor are found in only a small fraction of cells which are responsible for the growth, maintenance and recurrence of the tumor. Although these cells show some features of immature cells and are able to produce all the other (more mature) cells, being responsible for the heterogeneity of the neoplasia, their gene expression pattern (and the chromatin conformation on which it depends) do not match the one of stem cells. In this case, it might be concluded that the initiating event(s) occurred in a cell which has already completed one or more stage in the normal differentiation pathway (Fig. 2, panel B). This could elucidate the well known correlation between the degree of differentiation and the aggressiveness of the tumor, which cannot be easily 
explained by mutations always occurring in the same stem cell.

This second interpretation of the CSC theory clearly is compatible for all the difficulties cited above which do not fit with the strict interpretation of the CSC theory. Indeed, a recent workshop seems to endorse this interpretation of the theory, also suggesting that more differentiated cells can eventually evolve to become a CSC (Clarke et al. 2006). However, the real innovative potential of this "sensu lato" theory is limited. Indeed, the existence of a more aggressive fraction in human tumors has always been recognized on experimental and clinical grounds, not least from the ability to recur when $99.99 \%$ of the tumor has disappeared. With this interpretation, the marker analysis and the inoculation in immunodepressed mice is only an additional approach to the study of the self-renewing fraction of the tumor. However, these studies could lead to a new approach to isolate and investigate these cells and test them for sensitivity to therapy, with the hope that the results obtained on these purified fractions in vitro could match the sensibility in vivo of the whole tumor. Therefore, from a practical point of view, even in this case the theory could be clinically relevant, but the conceptual novelty will be low.

\section{References}

Adams JM, Kelly PN, Dakic A, Nutt SL, Strasser A (2007) Response to comment on "tumor growth need not be driven by rare cancer stem cells". Science $318: 1722$ d. doi: 10.1126/science. 1149672

Al-Hajj M, Wicha MS, Benito-Hernandez A, Morrison SJ, Clarke MF (2003) Prospective identification of tumorigenic breast cancer cells. Proc Natl Acad Sci USA 100:3983-3988

Bao S, Wu Q, McLendon RE, Hao Y, Shi Q, Hjelmeland AB, Dewhirst MW, Bigner DD, Rich JN (2006) Glioma stem cells promote radioresistance by preferential activation of the DNA damage response. Nature 444:756-760

Bonnet D, Dick JE (1997) Human acute myeloid leukemia is organized as a hierarchy that originates from a primitive hematopoietic cell. Nat Med 3:730-737

Chiba T, Kita K, Zheng YW, Yokosuka O, Saisho H, Iwama A, Nakauchi H, Taniguchi H (2006) Side population purified from hepatocellular carcinoma cells harbors cancer stem cell-like properties. Hepatology 44:240-251

Clarke MF, Dick JE, Dirks PB, Eaves CJ, Jamieson CH, Jones DL, Visvader J, Weissman IL, Wahl GM (2006) Cancer stem cells-perspectives on current status and future directions: AACR Workshop on cancer stem cells. Cancer Res 66:9339-9344

Dalerba P, Dylla SJ, Park IK, Liu R, Wang X, Cho RW, Hoey T, Gurney A, Huang EH, Simeone DM, Shelton AA, Parmiani G, Castelli C, Clarke MF (2007) Phenotypic characterization of human colorectal cancer stem cells. Proc Natl Acad Sci USA 104:10158-10163

Dontu G, Abdallah WM, Foley J, Jackson K, Clarke MF, Kawamura M, Wicha M (2007) In vitro propagation and transcriptional profiling of human mammary stem/progenitor cells. Genes Dev 17:1253-1270

Fang D, Nguyen TK, Leishear K, Finko R, Kulp AN, Hotz S, Van Belle PA, Xu X, Elder DE, Herlyn M (2005) Tumorigenic subpopulation with stem cell properties in melanomas. Cancer Res 65:9328-9337

Galli R, Binda E, Orfanelli U, Cipelletti B, Gritti A, De Vitis S, Fiocco R, Foroni C, Dimeco F, Vescovi A (2004) Isolation and characterization of tumorigenic, stem-like neural precursors from human glioblastoma. Cancer Res 64:7011-7021

Greaves M, Janossy G (1978) Patterns of gene expression and the cellular origins of human leukaemias. Biochim Biophys Acta 516:193-230

Hanahan D (1989) Transgenic mice as probes into complex systems. Science 246:1265-1275

Ho MM, Ng AV, Lam S, Hung JY (2007) Side population in human lung cancer cell lines and tumors is enriched with stem-like cancer cells. Cancer Res 67:4827-4833

Jaenisch R, Young R (2008) Stem cells, the molecular circuitry of pluripotency and nuclear reprogramming. Cell 132: 567-582

Kelly PN, Dakic A, Adams JM, Nutt SL, Strasser A (2007) Tumor growth need not be driven by rare cancer stem cells. Science $317: 337$

Knoblich JA (2008) Mechanisms of asymmetric stem cell division. Cell 132:583-597

Lapidot T, Sirard C, Vormoor J, Murdoch B, Hoang T, Caceres-Cortes J, Minden M, Paterson B, Caligiuri MA, Dick JE (1994) A cell initiating human acute myeloid leukaemia after transplantation into SCID mice. Nature 367:645-648

Li C, Heidt DG, Dalerba P, Burant CF, Zhang L, Adsay V, Wicha M, Clarke MF, Simeone DM (2007) Identification of pancreatic cancer stem cells. Cancer Res 67:10301037

Lobo NA, Shimono Y, Qian D, Clarke MF (2007) The biology of cancer stem cells. Annu Rev Cell Dev Biol 23:675-699

O'Brien CA, Pollett A, Gallinger S, Dick JE (2007) A human colon cancer cell capable of initiating tumour growth in immunodeficient mice. Nature 445:106-110

Patrawala L, Calhoun T, Schneider-Broussard R, Li H, Bhatia B, Tang S, Reilly JG, Chandra D, Zhou J, Claypool K, Coghlan L, Tang DG (2006) Highly purified CD44 ${ }^{+}$ prostate cancer cells from xenograft human tumors are enriched in tumorigenic and metastatic progenitor cells. Oncogene 25:1696-1708

Patrawala L, Calhoun-Davis T, Schneider-Broussard R, Tang DG (2007) Hierarchical organization of prostate cancer cells in xenograft tumors: the $\mathrm{CD} 44^{+} \alpha 2 \beta 1^{+}$cell population is enriched in tumor-initiating cells. Cancer Res 67:6796-6805 
Piccirillo SG, Reynolds BA, Zanetti N, Lamorte G, Binda E, Broggi G, Brem H, Olivi A, Dimeco F, Vescovi AL (2006) Bone morphogenetic proteins inhibit the tumorigenic potential of human brain tumour-initiating cells. Nature 444:761-765

Ponti D, Costa A, Zaffaroni N, Pratesi G, Petrangolini G, Coradini D, Pilotti S, Pierotti M, Daidone MG (2005) Isolation and in vitro propagation of tumorigenic breast cancer cells with stem/progenitor cell properties. Cancer Res 65:5506-5511

Prince ME (2007) Identification of a subpopulation of cells with cancer stem cell properties in head and neck squamous cell carcinoma. Proc Natl Acad Sci USA 104:973978

Ricci-Vitiani L, Lombardi DG, Pilozzi E, Biffoni M, Todaro M, Peschle C, De Maria R (2007) Identification and expansion of human colon-cancer-initiating cells. Nature 445:111-115

Schatton T, Murphy GF, Frank NY, Yamaura K, WaagaGasser AM, Gasser M, Zhan Q, Jordan S, Duncan LM, Weishaupt C, Fuhlbrigge RC, Kupper TS, Sayegh MH,
Frank MH (2008) Identification of cells initiating human melanomas. Nature 451:345-349

Singh SK, Clarke ID, Terasaki M, Bonn VE, Hawkins C, Squire J, Dirks PB (2003) Identification of a cancer stem cell in human brain tumors. Cancer Res 63:5821-5828

Singh SK, Hawkins C, Clarke ID, Squire JA, Bayani J, Hide T, Henkelman RM, Cusimano MD, Dirks PB (2004) Identification of human brain tumour initiating cells. Nature 432:396-401

Szotek PP, Pieretti-Vanmarcke R, Masiakos PT, Dinulescu DM, Connolly D, Foster R, Dombkowski D, Preffer F, Maclaughlin DT, Donahoe PK (2006) Ovarian cancer side population defines cells with stem cell-like characteristics and mullerian inhibiting substance responsiveness. Proc Natl Acad Sci USA 103:11154-11159

Wang J, Guo LP, Chen LZ, Zeng YX, Lu SH (2007) Identification of cancer stem cell-like side population cells in human nasopharyngeal carcinoma cell line. Cancer Res 67:3716-3724

Wicha MS, Liu S, Dontu G (2006) Cancer stem cells: an old idea-a paradigm shift. Cancer Res 66:1883-1890 